\title{
Use Of Atypical Anti-Psychotics In The Management Of Post-Traumatic Confusional States In Traumatic Brain Injury
}

\author{
MJ Temple
}

\begin{abstract}
The use of atypical anti-psychotics (AAP) in the treatment of organic neuropsychiatric syndromes is little reported. We present a case of posttraumatic delirium with delusions treated with Risperidone and discuss the use of AAP's in this situation.
\end{abstract}

\section{Case Presentation}

A 52-year-old married bus driver, previously fit and well, fell 20 foot from a ladder and sustained a closed head injury. CT revealed a left parietal subarachnoid bleed, right temporal intra-cerebral contusion and basal skull fracture. After 10 days in neuro-ICU where he was ventilated and treated conservatively he was transferred to the neurology ward.

He remained mildly disorientated and seemed to be progressing well. In week 3, after seeing the emergency helicopter land, he began expressing ideas of having been a fighter pilot and although no longer serving he was insistent on past involvement in various "missions", specifically South America. He developed ideas that the staff were military and felt his family were somehow at risk. He had visual hallucinations of military personnel walking around the ward talking unintelligibly to him, and described them as his "troops". He was disorientated in time, less so place, with nocturnal worsening of his symptoms. His cognitive function deteriorated further with difficulty sustaining concentration and attention and performing simple tasks. Investigations for other causes for his presentation were negative.

There was no past or family psychiatric history. He had a medical history of ChurgStauss Vasculitis treated with azathioprine and associated secondary pernicious anaemia. He had a long-standing interest in military matters, documentaries and joked of Army service with his grandchildren.

There was good response and minimal Sqn Ldr M J Temple MRCPsych

SpR Liaison Psychiatry, Dept Liaison

Psychiatry,

Leeds General

Infirmary,

Leeds.

email:

meljaynetempl@aol.com to be extra-pyramidal symptoms (EPS). Cessation of his Risperidone resulted in full resolution of his symptoms but the return of his delusions. Risperidone was subsequently re-started at $0.5 \mathrm{mg}$ to good effect without the re-emergence of EPS. With specialist rehabilitation he made a good recovery and the Risperidone was discontinued after 8 weeks. A more chronic post-traumatic confusional or psychotic state did not develop and he developed full insight into his experiences without psychological sequelae.

\section{Discussion}

Delirium occurring after traumatic brain injury has a variety of presentations including agitation and psychotic features and may occur after a period of clear consciousness in the recovery phase. Around $3-4 \%$ of presentations have associated delusions (1). Symptoms may resolve completely or leave residual difficulties from mild neuroses to posttraumatic dementia. Aetiological factors at the time other than the head injury itself must be sought in all cases. Pathophysiological processes within the injured brain heighten the risk of subsequent seizures and increase sensitivity to neuroleptics. Co-existing medical conditions and medications must be noted.

Recommendations for management in delirium $(2,3)$ tend to relate to non-trauma delirium and offer little guidance in this particular area. They focus on conventional neuroleptics, particularly haloperidol, though for neuroleptics licensing and dose details (4) are for use in functional rather than organic states.

Current specific post head injury management advice $(5,6,7)$ alongside the usual recommendations of nursing/ environmental strategies, includes avoidance of highly epileptogenic medication, minimisation of anticholinergic activity to avoid increased confusion and agitation, and care in use of potent antidopmaminergics due to increase sensitivity to extra-pyramidal side effects and akathisia. Use of medication with fewer active metabolites helps minimise drug interactions. The use of neuro-protective agents in head injury remains in its infancy (8) and within this is the issue what part antipsychotic medication should play and whether it may be deleterious to the recovery process (9). 
As the AAP's have lower potential for EPS, akathisia and fewer anti-cholinergic properties they would appear well suited for this condition. There are no randomised controlled trials in this area but uncontrolled case series report $(10,11$, 12,13 ) indicate a response in delirium symptoms similar to haloperidol with less EPS and sedation - Olanzapine (5-10mg) and Risperidone (1.5-4mg). However, as the post-traumatic brain is sensitive, care must still be taken in their use as side effects do occur and may include neuroleptic malignant syndrome (14). Behavioural disturbance may restrict their use until IM preparations are available Olanzapine IM is expected shortly.

\section{Acknowledgement}

Many thanks to Lt Col I Palmer MRCPsych, Prof Mil Psych, for his keen eye and guidance in the preparation of this report.

\section{References}

1. Violon A. Post-traumatic Psychoses. Acta Neurochem Supp (Wien) 1998;44:67-69.

2. Meagher DJ. Delirium: Optimising Management. BMF 2001;322:144-9.

3. American Psychiatric Association Practice Guidelines. Treatment of Psychiatric Disorders Compendium 2000.

4. British National Formulary.

5. Aramegas DB et al. Neuropsychiatric aspects of Traumatic Brain Injury. Current Treatment Options in Neurology 2000 Mar 2(2).

6. The Maudsley Guidelines 2001.

7. Eames P. Traumatic Brain Injury. Current Opinion in Psychiatry 1997;10:49-52.

8. Wasserberg J. Treating Head Injuries. BMJ 2002;325:454-5

9. Goldstein LB. Basic and Clinical Studies of the pharmacologic effects of recovery from brain injury fournal Neural Transplant Plast. 1994;277-8.

10. Sipahimalani A, Masand PS. Use of Risperidone in Delirium: case reports. Ann Clin Psychiatry 1997; 9:105-7.

11. Sipahimalani A et al. Treatment of Delirium with Risperidone. Int $\mathcal{f}$ Geriatric Psychopharmacology 1997; 1:24-26.

12. Sipahimalani A, Prakash S. Olanzapine in Delirium. Psychosomatics 39:422-430.

13. Zimmtzky et al. Use of Risperidone in psychotic disorder following ischaemic brain damage. $\mathcal{F}$ Child Adolesc Psychopharm 1996 Spring; 6(1):75-78

14. Watts D. NMS in a case of Acute Traumatic Psychosis British Fournal of Psychiatry 1991; Aug 159:277-8. 